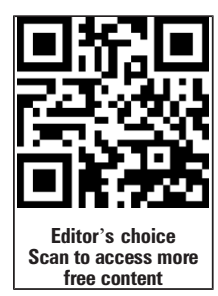

'Division of Reproductive Health, Centers for Disease Control and Prevention, Atlanta, Georgia, USA ${ }^{2}$ Division of Epidemiology, College of Public Health, The Ohio State University, Columbus, OH, USA ${ }^{3}$ Division of HIV/AIDS Prevention, Centers for Disease Control and Prevention, Atlanta, Georgia, USA ${ }^{4}$ Center for Health Equity Research, California State University, Long Beach,

California, USA

${ }^{5}$ Rietmeijer Consulting, LLC, Denver, Colorado, USA

${ }^{6}$ David Geffen School of Medicine and Fielding School of Public Health, University of California-Los Angeles, Los Angeles, California, USA ${ }^{7}$ Health and Human Development, EDC, Waltham, Massachusetts, USA

\section{Correspondence to} Dr Maria F Gallo, Division of Epidemiology, College of Public Health, The Ohio State University, 324 Cunz Hall, 1841 Neil Avenue Columbus, OH 43210-1351, USA; mgallo@cph.osu.edu

Received 8 December 2014 Revised 10 November 2015 Accepted 14 November 2015 Published Online First 15 December 2015

\title{
Sexual abstinence and other behaviours immediately following a new STI diagnosis among STI clinic patients: Findings from the Safe in the City trial
}

\author{
Maria F Gallo, ${ }^{1,2}$ Andrew D Margolis, ${ }^{3}$ C Kevin Malotte, ${ }^{4}$ Cornelis A Rietmeijer, ${ }^{5}$ \\ Jeffrey D Klausner, ${ }^{6}$ Lydia O'Donnell, ${ }^{7}$ Lee Warner, ${ }^{1}$ for the Safe in the City Study Group
}

\begin{abstract}
Background Few studies have assessed patients' sexual behaviours during the period immediately following a new diagnosis of a curable sexually transmitted infection (STI).
\end{abstract}

Methods Data were analysed from a behavioural study nested within the Safe in the City trial, which evaluated a video-based STI/HIV prevention intervention in three urban STI clinics. We studied 450 patients who reported having received a new STI diagnosis, or STI treatment, 3 months earlier. Participants reported on whether they seriously considered, attempted and succeeded in adopting seven sex-related behaviours in the interval following the diagnostic visit. We used multivariable logistic regression to identify, among men, correlates of two behaviours related to immediately reducing reinfection risk and preventing further STI transmission: sexual abstinence until participants were adequately treated and abstinence until their partners were tested for STIs.

Results Most participants reported successfully abstaining from sex until they were adequately treated for their baseline infection (89\%-90\%) and from sex with potentially exposed partners until their partners were tested for HIV and other STIs (66\%-70\%). Among men who intended to be abstinent until they were adequately treated, those who did not discuss the risks with a partner who was possibly exposed were more likely not to be abstinent $(\mathrm{OR}, 3.7 ; 95 \% \mathrm{Cl} 1.5$ to 9.0) than those who had this discussion. Similarly, among men who intended to abstain from sex with any potentially exposed partner until the partner was tested for HIV and other STIs, those who reported not discussing the risks of infecting each other with HIV/STIs were more likely to be sexually active during this period $(\mathrm{OR}, 3.5 ; 95 \% \mathrm{Cl} 1.6$ to 8.1$)$ than were those who reported this communication.

Conclusions Improved partner communication could facilitate an important role in the adoption of protective behaviours in the interval immediately after receiving a new STI diagnosis.

Trial registration number NCT00137670.

\section{CrossMark}

To cite: Gallo MF Margolis AD, Malotte CK, et al. Sex Transm Infect 2016:92:206-210

\section{INTRODUCTION}

Sexually transmitted infections (STIs) remain a critical public health issue with an estimated 499 million new cases of chlamydial infection, gonorrhoea, syphilis and trichomoniasis occurring annually worldwide. ${ }^{1}$ Repeat infections also occur frequently with reinfection rates for chlamydia and gonorrhoea reaching as high as $32 \%$ and $40 \%$ in women, ${ }^{2}$ and $18 \%$ and $31 \%$ in men, respectively. ${ }^{3}$ Patients newly diagnosed with a curable STI represent an important target population for preventing reinfection, as well as for avoiding further transmission to sexual partners. Risk factors for reinfection with gonorrhoea or chlamydia include young age, minority race or ethnicity, having multiple or new partners, failing to attend a clinical treatment appointment, previous history of an STI, continuing to have sex with a partner not known to have been treated and being a man who has sex with men. ${ }^{3-9}$

Despite research on STI risk factors and reinfection rates, few studies have examined the sexual behaviours of patients immediately following receipt of a new STI diagnosis. ${ }^{10-14}$ We describe reports by STI clinic patients of their seriously considering, attempting and successful adopting multiple behaviours related to sex and relationships during the immediate interval after their being diagnosed with or treated for a new curable STI. Given longstanding recommendations by the US Centers for Disease Control and Prevention (CDC) and European health agencies to abstain from sex while undergoing treatment for STI, ${ }^{15}{ }^{16}$ we also evaluated behavioural characteristics of male participants reporting failure to be abstinent until they were adequately treated and until their partners were tested for HIV and other STIs.

\section{MATERIALS AND METHODS}

We analysed data from a behavioural study nested within the Safe in the City trial, which was conducted in public STI clinics in three US cities (Denver, Colorado, USA; Long Beach and San Francisco, California, USA) during 2003-2005. The trial systematically allocated 4-week intervals alternating with and without the Safe in the City intervention, a theory-based video on safer sex, playing in the clinic waiting-room. ${ }^{17}$ The main trial involved review of medical records for 38635 STI clinic patients and demonstrated that patients initially attending the clinics during an interval where the waiting-room video was being shown ('intervention interval') had a $9 \%$ decrease in new laboratory-confirmed STIs (ie, gonorrhoea, chlamydia, trichomoniasis, syphilis and HIV infection) during study follow-up compared with patients initially attending during an interval where the video was not playing ('control interval'). The per-patient 
cost of producing the video and implementing the intervention was estimated at $\$ 0.46 .{ }^{18}$ Additional details regarding the design and results of the Safe in the City trial have been reported elsewhere. ${ }^{17}$

In the nested study, a systematically drawn sample of male and female STI clinic patients from both intervention and control study conditions in the original trial completed audio computer-assisted self-interview (ACASI) surveys. These surveys were conducted immediately following the baseline clinic visit (ie, before the patient departed the clinic) and at a 3-month visit. English-speaking patients in the three study clinics were eligible for the nested study if they were $\geq 18$ years of age, reported engaging in vaginal or anal intercourse in the last 3 months, reported having been in the clinic waiting-room for at least 20 min during the baseline visit and were not known by the clinician or counsellor to be HIV positive, pregnant or seriously ill. Patients who had a condition requiring frequent clinic visits for treatment (eg, human papillomavirus or herpes) or who had previously attended a participating clinic during an intervention interval when the video was played were ineligible. The protocol (\#3500) was approved by the Institutional Review Board at the CDC and at the study sites (University of California, San Francisco and at Long Beach; the University of Colorado Hospital and Education Development Center).

The study population for the present analysis consisted of all participants in the nested study who completed the 3-month follow-up assessment and who reported having been diagnosed or treated during their baseline visit for $\geq 1$ curable STI (ie, gonorrhoea, chlamydia, trichomoniasis, primary or secondary syphilis, mucopurulent cervicitis or non-gonococcal urethritis). Although participants could have inaccurately recalled their STI history, we wanted to focus on those who thought (even erroneously) that they had recently had an infection. Participants were assessed on whether they 'seriously considered', 'attempted to adopt' and 'succeeded in adopting' (distinct questions) in accomplishing seven behaviours related to sex or relationships in the 3-month period following the baseline visit. These behaviours consisted of the following: (1) abstaining from sex until the participant was adequately treated, (2) abstaining from sex with any potentially exposed partner until the partner was tested for HIV and other STIs, (3) discussing the risks with a partner who was possibly exposed, (4) telling a potentially exposed partner to seek an STI examination, (5) breaking up with a partner who exposed participant to STI, (6) discussing with a partner the risks of infecting each other with HIV/STIs and (7) abstaining from sex when drinking or using drugs.

We identified correlates of the two self-reported behaviours that relate directly to the immediate risk of reinfection or further transmission of infection: (1) failing to abstain from sex until the participant was adequately treated and (2) failing to abstain from sex with any potentially exposed partner until the partner was tested for HIV and other STIs. The analyses to identify correlates were restricted to those reporting that they 'seriously considered' engaging in the given type of abstinence. The analyses to identify correlates were restricted a priori to male participants because the sample of women was insufficient in size. We assessed as potential correlates participant reports of succeeding in accomplishing the other behaviours related to sex or relationships listed above and the number of partners in the past 3 months ( 0 or 1,2 vs $\geq 3$ ). We fit two full multivariable logistic models (one for each abstinence outcome) with potential correlates and then used stepwise backward elimination to reduce the model by removing factors that were not associated (based on a $\mathrm{p}$ value $\leq 0.05$ ) with the outcome.

\section{RESULTS}

Among the 1609 participants enrolled in the nested behavioural study, 1392 (87\%) completed the 3-month follow-up assessment. Among this subset, 450 (32\%) reported having received a new STI diagnosis or treatment for an STI at their baseline visit, and therefore comprise the analysis population for this report. Most of these participants were men $(76 \%), \geq 25$ years of age (61\%), heterosexual (77\%) and single (74\%) (table 1). The most common reason for the baseline visit was having new symptoms (48\%).

In general, for each of the seven behaviours assessed following the baseline visit, few male or female participants reported that they 'seriously considered' the given behaviour without also having 'attempted' or 'succeeded' in adopting the behaviour (tables 2 and 3). Likewise, few reported having attempted towithout having succeeded in-adopting the behaviour. For example, $89 \%$ of men and $90 \%$ of women succeeded in adopting the recommended risk-reduction behaviour of abstaining from sex until they were adequately treated. However, few men and women reported only having seriously considered it $(2 \%$ and $0 \%$, respectively) with no further action, and few men and women attempted without also succeeding in adopting it (7\% and $9 \%$, respectively). The sole exception was that large differences existed between the proportions of men and women who only 'seriously considered' breaking up with a partner with no

Table 1 Characteristics of patients with STI reporting baseline receipt of STI diagnosis or treatment, by sex

\begin{tabular}{|c|c|c|c|}
\hline & $\begin{array}{l}\text { Men } \\
(n=340)\end{array}$ & $\begin{array}{l}\text { Women } \\
(n=110)\end{array}$ & $\begin{array}{l}\text { Total } \\
(n=450)\end{array}$ \\
\hline & No. $(\%)$ & No. $(\%)$ & No. $(\%)$ \\
\hline \multicolumn{4}{|l|}{ Age } \\
\hline$<25$ years & $115(33.8)$ & $61(55.5)$ & $176(39.1)$ \\
\hline$\geq 25$ years & $225(66.2)$ & $49(44.6)$ & $274(60.9)$ \\
\hline \multicolumn{4}{|l|}{ Race or ethnicity } \\
\hline White, non-Hispanic & $111(32.7)$ & $26(23.6)$ & $137(30.4)$ \\
\hline Black, non-Hispanic & $135(39.7)$ & $42(30.1)$ & $178(39.6)$ \\
\hline Hispanic & $73(21.5)$ & $29(26.4)$ & $102(22.7)$ \\
\hline Other/missing & $21(6.2)$ & $12(10.9)$ & $33(7.3)$ \\
\hline \multicolumn{4}{|l|}{ Highest level of education completed } \\
\hline$\leq$ High school or equivalent & $129(37.9)$ & $57(51.8)$ & $186(41.3)$ \\
\hline$>$ High school & $211(62.1)$ & $53(48.2)$ & $264(58.7)$ \\
\hline \multicolumn{4}{|l|}{ Marital status* } \\
\hline Single & $254(74.9)$ & $76(69.1)$ & $330(73.5)$ \\
\hline Married, cohabiting or domestic partner & $64(18.9)$ & $21(19.1)$ & $85(18.9)$ \\
\hline Divorced or widowed & $21(6.2)$ & $13(11.8)$ & $34(7.6)$ \\
\hline \multicolumn{4}{|l|}{ Site } \\
\hline Denver & $95(27.9)$ & $23(20.9)$ & $118(26.2)$ \\
\hline San Francisco & $140(41.2)$ & $55(50.0)$ & $195(43.3)$ \\
\hline Long Beach & $105(30.9)$ & $32(29.1)$ & $137(30.4)$ \\
\hline \multicolumn{4}{|l|}{ Sexual identity } \\
\hline Heterosexual & $248(72.9)$ & $97(88.2)$ & $345(76.7)$ \\
\hline Gay/lesbian, bisexual & $92(27.1)$ & $13(11.8)$ & $105(23.3)$ \\
\hline \multicolumn{4}{|l|}{ Reason for baseline visit* } \\
\hline New symptoms & $174(51.2)$ & $43(39.1)$ & $217(48.3)$ \\
\hline Contact to an STI & $90(26.5)$ & $33(30.0)$ & $123(27.4)$ \\
\hline Othert & $75(22.1)$ & 34 (30.9) & 109 (24.3) \\
\hline
\end{tabular}

${ }^{*} \mathrm{~N}=339$ men.

tCould include visit for routine STI screening or examination, follow-up on positive test, HIV testing, emergency contraception or other contraception. STI, sexually transmitted infection. 
Table 2 Reports of having seriously considered, attempted and succeeded in adopting behaviours during the interval immediately following a new STI diagnosis or treatment, men $(n=340)$

\begin{tabular}{|c|c|c|c|c|}
\hline & $\begin{array}{l}\text { Did not consider, attempt or } \\
\text { successfully adopt } \\
\text { No. (\%) }\end{array}$ & $\begin{array}{l}\text { Seriously considered the } \\
\text { behaviour* } \\
\text { No. (\%) }\end{array}$ & $\begin{array}{l}\text { Attempted to } \\
\text { adopt the } \\
\text { behaviourt } \\
\text { No. }(\%)\end{array}$ & $\begin{array}{l}\text { Succeeded in } \\
\text { adopting the } \\
\text { behaviour } \\
\text { No. (\%) }\end{array}$ \\
\hline Abstaining from sex until adequately treated & $6(1.8)$ & $6(1.8)$ & $24(7.1)$ & $304(89.4)$ \\
\hline $\begin{array}{l}\text { Abstaining from sex with potentially exposed partner until } \\
\text { the person was tested for HIV and other STIs }\end{array}$ & $53(15.6)$ & $13(3.8)$ & $37(10.9)$ & $237(69.7)$ \\
\hline Discussing the risks with a partner who was possibly exposed & $14(4.1)$ & $30(8.8)$ & $15(4.4)$ & $281(82.7)$ \\
\hline $\begin{array}{l}\text { Telling a potentially exposed partner to seek an STI } \\
\text { examination }\end{array}$ & $14(4.1)$ & $36(10.6)$ & $6(1.8)$ & $284(83.5)$ \\
\hline Breaking up with a partner who exposed participant to STI & $103(30.8)$ & $61(18.2)$ & 40 (11.9) & $131(39.1)$ \\
\hline $\begin{array}{l}\text { Discussing with a partner the risks of infecting each other } \\
\text { with HIV/STIs }\end{array}$ & $26(7.7)$ & $25(7.4)$ & $10(3.0)$ & $277(82.0)$ \\
\hline Abstaining from sex when drinking or using drugs & $115(34.5)$ & $16(4.8)$ & $32(9.6)$ & $170(51.1)$ \\
\hline
\end{tabular}

${ }^{*}$ Among those not reporting having attempted or succeeded in adopting the behaviour.

tAmong those not reporting having succeeded in adopting the behaviour.

STI, sexually transmitted infection.

further action (18\% and 12\%, respectively) or having attempted to break up without then succeeding in doing so $(12 \%$ and $17 \%$, respectively).

Among 321 male participants who reported an intention ('seriously considered') to abstain from sex until they received adequate STI treatment, $8 \%(n=24)$ reported failure to succeed in adopting this behaviour. In the bivariable analyses, three correlates of failure to abstain until having received adequate treatment were identified: not discussing the risks with a partner who was possibly exposed (OR, 3.7; 95\% CI 1.5 to 9.0), not telling a partner who might have been exposed to seek an STI examination (OR, 3.3; 95\% CI 1.3 to 8.1) and not discussing with a partner the risks of infecting each other with HIV/STIs (OR, 3.5; 95\% CI 1.4 to 8.5) (table 4). In the multivariable analysis, only not discussing risks with a partner who was possibly exposed remained statistically significant.

Among the 259 men who stated that they intended to abstain from sex with any potentially exposed partner until the partner was tested for HIV and other STIs, 15\% $(n=39)$ admitted that they were not abstinent. Only one factor was associated in the bivariable analyses with abstaining from sex until their potentially exposed partner was tested: male participants who failed to discuss with a partner the risks of infecting each other with HIV/STIs were more likely to report failure to remain abstinent until treatment (OR, 3.5; 95\% CI 1.6 to 8.1) than were men who had this discussion (table 4). No other factor emerged as significant in the multivariable analysis.

\section{DISCUSSION}

Most participants reported contemplating and implementing sexual-risk-reduction behaviours following receipt of a new STI diagnosis. Most notably, high proportions of male and female participants reported successfully abstaining from sex until they were adequately treated for their baseline infection (89\%-90\%) or until their partners who were potentially exposed were tested for HIV and other STIs (66\%-70\%). These results are consistent with other studies demonstrating the adoption of protective behaviours after receiving an STI diagnosis. For example, a study conducted among Mexican-American and African-American women diagnosed with a non-viral STI found that $83 \%-90 \%$ of participants reported abstaining from sex with an untreated partner in the interval following diagnosis. ${ }^{10}$

Table 3 Reports of having seriously considered, attempted, and succeeded in adopting behaviours during the interval immediately following a new STI diagnosis or treatment, women $(n=110)$

\begin{tabular}{|c|c|c|c|c|}
\hline & $\begin{array}{l}\text { Did not consider, attempt } \\
\text { or successfully adopt } \\
\text { No. }(\%)\end{array}$ & $\begin{array}{l}\text { Seriously considered } \\
\text { the behaviour* } \\
\text { No. }(\%)\end{array}$ & $\begin{array}{l}\text { Attempted to } \\
\text { adopt the behaviourt } \\
\text { No. (\%) }\end{array}$ & $\begin{array}{l}\text { Succeeded in } \\
\text { adopting } \\
\text { the behaviour } \\
\text { No. }(\%)\end{array}$ \\
\hline Abstaining from sex until adequately treated & $1(0.9)$ & $0(0.0)$ & $10(9.1)$ & $99(90.0)$ \\
\hline $\begin{array}{l}\text { Abstaining from sex with potentially exposed partner until the } \\
\text { person was tested for HIV and other STIs }\end{array}$ & $11(10.0)$ & 7 (6.4) & 19 (17.3) & $73(66.4)$ \\
\hline Discussing the risks with a partner who was possibly exposed & $1(0.9)$ & $5(4.6)$ & $4(3.6)$ & $100(90.9)$ \\
\hline Telling a potentially exposed partner to seek an STI examination & $1(0.9)$ & $6(5.5)$ & $6(5.5)$ & $97(88.2)$ \\
\hline Breaking up with a partner who exposed participant to STI & $34(30.9)$ & $13(11.8)$ & $19(17.3)$ & $44(40.0)$ \\
\hline $\begin{array}{l}\text { Discussing with a partner the risks of infecting each other with } \\
\text { HIV/STIs }\end{array}$ & $5(4.6)$ & $2(1.8)$ & $4(3.6)$ & $99(90.0)$ \\
\hline Abstaining from sex when drinking or using drugs & $32(29.1)$ & $4(3.6)$ & $6(5.5)$ & $68(61.8)$ \\
\hline
\end{tabular}


Also, three multicity studies of adolescents found lower rates of reports of unprotected sex following the receipt of a positive STI diagnosis. ${ }^{11-13}$

Patients often fail to disclose a positive STI diagnosis with partners for reasons that include guilt, fear of stigma, embarrassment, denial or concern about effects on their relationship. ${ }^{14}$ Partner communication in the present study, though, appeared important for successfully achieving abstinence. Among men who intended to be abstinent until they were adequately treated, discussing the risks with a partner who was possibly exposed was associated with succeeding in being abstinent until receiving adequate treatment. Similarly, among men who reported seriously considering abstaining from sex with any potentially exposed partner until the partner was tested for HIV and other STIs, those who discussed the risks of infecting each other with HIV/STIs were more likely to report achieving this abstinence than those who failed to have this partner communication.

For many of the sexual-risk-reduction behaviours evaluated, few participants reporting seriously considering a given behaviour without also attempting or succeeding in adopting it during the interval following a new STI diagnosis. Likewise, few reported attempting a given behaviour without also successfully adopting it. Given this pattern, asking patients who test positive for a new infection about their intentions could be a useful proxy for predicting the likelihood of success; additional

Table 4 Unadjusted OR for association with reporting failure to abstain from sex until adequately treated or until partner was tested for HIV and other STIs, among men reporting having 'seriously considered' the behaviour

\begin{tabular}{|c|c|c|c|c|}
\hline & \multicolumn{2}{|c|}{$\begin{array}{l}\text { Reporting failure to abstain } \\
\text { from sex until adequately } \\
\text { treated } \\
(\mathrm{n}=321)\end{array}$} & \multicolumn{2}{|c|}{$\begin{array}{l}\text { Reporting failure to abstain } \\
\text { from sex with potentially } \\
\text { exposed partner until partner } \\
\text { was tested for HIV/STIs } \\
(\mathrm{n}=259)\end{array}$} \\
\hline & No. $(\%)$ & OR $(95 \% \mathrm{Cl})$ & No. $(\%)$ & OR $(95 \% \mathrm{Cl})$ \\
\hline \multicolumn{5}{|c|}{ Number of partners in the past 3 months } \\
\hline 0.1 & $12(6.9)$ & 1.0 & $19(12.8)$ & 1.0 \\
\hline 2 & $3(5.1)$ & $0.7(0.2$ to 2.7$)$ & $8(15.7)$ & $1.3(0.5$ to 3.1$)$ \\
\hline$\geq 3$ & $9(10.2)$ & $1.5(0.6$ to 3.8$)$ & $12(20.3)$ & 1.7 (0.8 to 3.9$)$ \\
\hline \multicolumn{5}{|c|}{ Discussed the risks with a partner who was possibly exposed } \\
\hline Yes & $15^{*}(5.6)$ & 1.0 & 31 (13.5) & 1.0 \\
\hline No & $9^{*}(18.0)$ & 3.7 (1.5 to 9.0$)$ & $8(26.7)$ & $2.3(1.0$ to 5.7$)$ \\
\hline \multicolumn{5}{|c|}{ Told a partner who might have been exposed to seek an STI examination } \\
\hline Yes & $16^{*}(5.9)$ & 1.0 & $33(14.2)$ & 1.0 \\
\hline No & $8^{*}(17.0)$ & $3.3(1.3$ to 8.1$)$ & $6(23.1)$ & $1.8(0.7$ to 4.9$)$ \\
\hline \multicolumn{5}{|c|}{ Broke up with a partner who put participant at risk of an STI } \\
\hline Yes & $9+(7.1)$ & 1.0 & $13 \ddagger(11.4)$ & 1.0 \\
\hline No & $13+(7.2)$ & $1.0(0.4$ to 2.5$)$ & $25 \ddagger(17.7)$ & 1.7 (0.8 to 3.4$)$ \\
\hline \multicolumn{5}{|c|}{ Discussed with a partner risks of infecting each other with HIV/STIs } \\
\hline Yes & $15 \S(5.7)$ & 1.0 & $28(12.4)$ & 1.0 \\
\hline No & $9 \S(17.3)$ & $3.5(1.4$ to 8.5$)$ & $11(33.3)$ & $3.5(1.6$ to 8.1$)$ \\
\hline \multicolumn{5}{|c|}{ Abstained from sex when drinking or using drugs ( $n=311$ and 252) } \\
\hline Yes & 8 8ा (4.9) & 1.0 & $18^{* *}(12.5)$ & 1.0 \\
\hline No & 159 (10.1) & $2.2(0.9$ to 5.3$)$ & $20 * *(18.5)$ & $1.6(0.8$ to 3.2$)$ \\
\hline \multicolumn{5}{|c|}{$\begin{array}{l}{ }^{*} \mathrm{n}=318 \text { due to missing values. } \\
\mathrm{tn}=308 \text { due to missing values. } \\
\neq \mathrm{n}=255 \text { due to missing values. } \\
\S \mathrm{n}=317 \text { due to missing values. } \\
\text { In } \mathrm{n}=311 \text { due to missing values. } \\
{ }^{* *} \mathrm{n}=252 \text { due to missing values. } \\
\mathrm{STI} \text {, sexually transmitted infection. }\end{array}$} \\
\hline
\end{tabular}

counselling could be directed toward trying to influence intentions among the patients who admit that they do not intend to carry out a behaviour. In contrast, most patients who report intending to conduct the behaviour may not need additional intervening to support this intention.

The similarities in the proportions of participants reporting seriously considering, attempting and succeeding in adopting specific sexual-risk-reduction behaviour could be the result of reporting bias. Reliance on participants' self-reports, which could have been affected by social desirability or recall bias, is a primary limitation of the study. For example, to please investigators in an STI clinic setting, some participants may have over-reported success in adopting preventive behaviours, including abstinence. The use of ACASI, which obviates the need for an interviewer, could have reduced the potential for reporting bias; however, the evidence of the effectiveness of ACASI on reducing bias is inconsistent. ${ }^{19} 20$ Self-reported STI diagnoses also are subject to error. ${ }^{21}$ However, the target population for this research consists of individuals who perceived that they recently received an STI diagnosis, making the preventive behaviours practiced in response to this belief relevant. An additional limitation is that the sample size of women did not permit the multivariable analysis of correlates of abstaining behaviours. Also, patterns of behaviours in the target population could have changed since the study was conducted roughly a decade ago. Finally, the study focused only on individual-level behaviours; the influence of other factors, such as sexual or social networks or other interventions, on the risk for reinfection was not explored.

The strengths of this analysis include the assessment of a range of potential correlates of recommended abstinence-related behaviour following STI diagnoses. Furthermore, the analysis benefited from its prospective cohort design in which patients were assessed for STIs and then later were administered the retrospective questionnaire on their behaviour during the interval following receipt of their STI diagnosis. Finally, the follow-up rate $(87 \%$ of those enrolled in the nested behavioural study) was high.

Interventions (eg, abstinence, mutual monogamy, condoms and the use of expedited partner treatment) have demonstrated effectiveness for preventing STIs, but replication and scale-up of these prevention strategies have been slow. ${ }^{22}{ }^{23}$ Controlling STIs in 'core' groups-subpopulations at elevated risk of STI acquisition and transmission - is thought to be a necessary (but not sufficient) step for adequately addressing infection in the overall population. ${ }^{24}$ Focusing on patients at STI clinics with high risk for subsequent infections could provide a practical and efficient way of identifying and intervening with core group transmitters (ie, those who are often infected or often transmit the infection). ${ }^{25}{ }^{26}$ One proposed strategy is to counsel patients to abstain from sex ${ }^{15}{ }^{16}$ or to use condoms consistently and correctly until treatment is completed; however, few studies on the effectiveness of these counselling interventions have been conducted. ${ }^{27}$ Interventions demonstrated to be effective in reducing subsequent STIs among index patients include displaying an educational video in the STI clinic waiting-room and notifying patients' partners about the infection and the need to receive treatment. ${ }^{17}{ }^{28}$ While the optimal strategy for partner notification (ie, patient referral, expedited partner therapy, contract referral and provider referral) of specific STIs may differ by patient, partner and situation, ${ }^{28}$ the present findings support the role of patient communication of the risks of infection with their partners. Future research could evaluate the feasibility and effectiveness of brief interventions to improve partner communication as a means to strengthen behaviours for avoiding transmission or reinfection among patients newly diagnosed with an STI. 


\section{Key messages}

- Most participants reported successfully abstaining from sex until receiving treatment for their baseline infection and until their potentially exposed partners were tested for HIV/ STIS.

- In general, for each of the seven behaviours assessed, few male or female participants reported that they 'seriously considered' the given behaviour without also having 'attempted' or 'succeeded' in adopting the behaviour in the period following their STI diagnosis.

- Partner communication was an important correlate for successfully achieving abstinence until adequate treatment or until partners were tested for HIV/STIS.

\section{Handling editor Jackie A Cassell}

Acknowledgements The study group thanks the administrative and clinical staff in each of the participating STD clinics for their support and contributions to the project. The Safe in the City Study Group includes the following individuals. CDCLee Warner, Andrew Margolis, Jocelyn Patterson, Craig Borkowf, David Purcell, Ann O'Leary, Fan Zhang, Terry Wang, Mary Neumann, Kashif Iqbal, Bob Byers, Gale Burstein, Thomas Peterman, Catherine Lindsey Satterwhite; Denver Public HealthCornelis Rietmeijer, John Douglas, Sheana Bull, Doug Richardson, Mark Foster, Stuart Cooper, Julie Caine, Rebecca Rothbard, Terry Sapp-Jones, Lesley Brooks; Education Development Center, Inc.-Lydia O'Donnell, Alexi San Doval, Athi MyintU, Richard Duran, Carl O'Donnell; Long Beach, California State University \& Department of Health and Human Services-Kevin Malotte, Shelley Vrungos, Nettie DeAugustine, Chris Kau, Inez Denson, Marina Ohlson Smorick, Ann Marie Bernhard; San Francisco Department of Public Health-Jeffrey Klausner, Gregory Greenwood, Carolyn Hunt, Elizabeth Varela, Kevin Filocamo, David Bandy.

Contributors CKM, CAR, JDK, LO and LW contributed to the study design and concept. AM, CKM, CAR and JDK participated in acquisition of data. MG, ADM and LW contributed to the statistical analysis. All authors participated in the drafting of the manuscript and have reviewed and approved the final version.

Disclaimer The findings and conclusions in this report are those of the authors and do not necessarily represent the official position of the CDC. The authors have no conflicts of interests.

Funding This study was funded by the Centers for Disease Control and Prevention through multisite federal cooperative agreements (921007, 821004 and 121005).

Competing interests None declared.

Ethics approval Centers for Disease Control and Prevention IRB \#3500.

Provenance and peer review Not commissioned; externally peer reviewed.

\section{REFERENCES}

1 World Health Organization. Global incidence and prevalence of selected curable sexually transmitted infections-2008. Geneva: WHO, 2012.

2 Hosenfeld CB, Workowski KA, Berman S, et al. Repeat infection with chlamydia and gonorrhea among females: a systematic review of the literature. Sex Transm Dis 2009;36:478-89.

3 Fung M, Scott KC, Kent CK, et al. Chlamydial and gonococcal reinfection among men: a systematic review of data to evaluate the need for retesting. Sex Transm Infect 2007:83:304-9.

4 Hughes G, Nichols T, Peters L, et al. Repeat infection with gonorrhoea in Sheffield, UK: predictable and preventable? Sex Transm Infect 2013;89:38-44.
5 Liu B, Guy R, Donovan B, et al. Chlamydia trachomatis re-infections in a population-based cohort of women. Sex Transm Infect 2013;89:45-50.

6 Niccolai LM, Livingston KA, Laufer AS, et al. Behavioural sources of repeat Chlamydia trachomatis infections: importance of different sex partners. Sex Transm Infect 2011:87:248-53.

7 Evans C, Das C, Kinghorn G. A retrospective study of recurrent chlamydia infection in men and women: is there a role for targeted screening for those at risk? Int J STD AIDS 2009:20:188-92.

8 Dunne EF, Chapin JB, Rietmeijer CA, et al. Rate and predictors of repeat Chlamydia trachomatis infection among men. Sex Transm Dis 2008;35:S40-4.

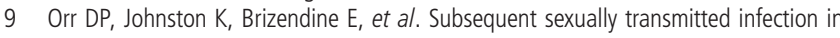
urban adolescents and young adults. Arch Pediatr Adolesc Med 2001;155:947-53.

10 Shain RN, Perdue ST, Piper JM, et al. Behaviors changed by intervention are associated with reduced STD recurrence: the importance of context in measurement. Sex Transm Dis 2002;29:520-9.

11 Sznitman SR, Carey MP, Vanable PA, et al. The impact of community-based sexually transmitted infection screening results on sexual risk behaviors of African American adolescents. J Adolesc Health 2010;47:12-19.

12 Crosby RA, DiClemente RJ, Wingood GM, et al. Associations between sexually transmitted disease diagnosis and subsequent sexual risk and sexually transmitted disease incidence among adolescents. Sex Transm Dis 2004;31:205-8.

13 Fortenberry JD, Brizendine EJ, Katz BP, et al. Post-treatment sexual and prevention behaviours of adolescents with sexually transmitted infections. Sex Transm Infect 2002;78:365-8.

14 Balfe M, Brugha R. Disclosure of STI testing activities by young adults: the influence of emotions and social networks. Sociol Health IIIn 2010;32:1041-58.

15 Centers for Disease Control and Prevention. Sexually transmitted diseases treatment guidelines. MMWR 2015;64(RR3):1-137.

16 Radcliffe K. European STD guidelines. Int J STD AIDS 2001;12:S1-102.

17 Warner L, Klausner JD, Rietmeijer CA, et al. Effect of a brief video intervention on incident infection among patients attending sexually transmitted disease clinics. PLoS Med 2008; 5:e135.

18 Gift TL, O'Donnell LN, Rietmeijer CA, et al. The program cost of a brief video intervention shown in STD clinic waiting rooms. Sex Transm Dis (in press).

19 Langhaug LF, Sherr L, Cowan FM. How to improve the validity of sexual behaviour reporting: systematic review of questionnaire delivery modes in developing countries. Trop Med Int Health 2010;15:362-81.

20 Minnis AM, Steiner MJ, Gallo MF, et al. Biomarker validation of reports of recent sexual activity: results of a randomized controlled study in Zimbabwe. Am J Epidemiol 2009;170:918-24.

21 Harrington KF, DiClemente RJ, Wingood GM, et al. Validity of self-reported sexually transmitted diseases among African American female adolescents participating in an HIVISTD prevention intervention trial. Sex Transm Dis 2001;28:468-71.

22 Manhart LE, Holmes KK. Randomized controlled trials of individual-level, population-level, and multilevel interventions for preventing sexually transmitted infections: what has worked? J Infect Dis 2005;191(Suppl 1):S7-24.

23 Scott-Sheldon LA, Fielder RL, Carey MP. Sexual risk reduction interventions for patients attending sexually transmitted disease clinics in the United States: a meta-analytic review, 1986 to early 2009. Ann Behav Med 2010;40:191-204.

24 Committee on Prevention and Control of Sexually Transmitted Diseases: Institute of Medicine. The hidden epidemic: confronting sexually transmitted diseases. Washington DC: National Academy Press, 1997

25 Gunn RA, Fitzgerald S, Aral So. Sexually transmitted disease clinic clients at risk for subsequent gonorrhea and chlamydia infections: possible 'core' transmitters. Sex Transm Dis 2000;27:343-9.

26 Thomas JC, Tucker MJ. The development and use of the concept of a sexually transmitted disease core. J Infect Dis 1996;174:S134-43.

27 Anderson C, Gallo MF, Hylton-Kong T, et al. Randomized controlled trial on the effectiveness of counseling messages for avoiding unprotected sexual intercourse during STI and RTI treatment among female patients. Sex Transm Dis 2013;40:105-10

28 Ferreira A, Young T, Mathews $C$, et al. Strategies for partner notification for sexually transmitted infections, including HIV. Cochrane Database Syst Rev 2013;10:CD002843. 